\title{
The influence of printing substrate on colorimetric properties of thermochromic offset prints
}

\author{
Marina Vukoje, Renato Glibo, Rahela Kulčar, Mirela Rožić \\ University of Zagreb, Faculty of Graphic Arts, Getaldićeva 2, 10000 Zagreb, Croatia \\ Corresponding author: Mirela Rožić, mirela.rozic@grf.hr
}

\begin{abstract}
This paper investigates the colorimetric properties of reversible thermochromic offset printing ink on different paper substrates. Reversible thermochromic (TC) printing ink is printed by offset printing on four different printing substrates. Colorimetric measurements are performed by measuring diffuse reflection by determining uniform measurable physical size in the CIELAB colour space of the examined sample at temperatures ranging from $35^{\circ} \mathrm{C}$ to $75^{\circ} \mathrm{C}$ during heating and at the same temperatures up to $20^{\circ} \mathrm{C}$. As the colour of the TC prints depends on the temperature, which results in colour hysteresis, it is noted that the colour hysteresis is affected by the printing substrate. The activation temperature given by the producer $\left(63^{\circ} \mathrm{C}\right)$, is above the obtained temperatures, for print on filter paper $61,3^{\circ} \mathrm{C}$, for print on synthetic paper $61,5^{\circ} \mathrm{C}$, for print on bulky paper $60,9^{\circ} \mathrm{C}$, with the highest deviation in the case of print on recycled paper $\left(59,4^{\circ} \mathrm{C}\right)$. The results of total colour difference of samples measured between heating and cooling at the temperature well below the final chromic temperature and the CIEDE2000 total colour difference between the samples in the heated and cooled state as a function of temperature showed that the highest colour difference was obtained in TC print on the filter paper.
\end{abstract}

Keywords: thermochromic ink, colorimetric properties, printing substrate, colour hysteresis

\section{Introduction}

Thermochromism is the specific ability of a substance, atomic group or material to change its optical state. Thermochromic mechanisms are based on the duration criterion on reversible (multiple and temporal changes in colour) and irreversible (one-off and permanent colour change). Reversible thermochromic organic materials usually consist of at least three components, namely a colour former, colour developer and solvent. The thermochromic effect is caused by the formation of leuco dye - developer complexes in a reversible equilibrium redox reaction between leuco dye and developer. The reaction is triggered by interactions between the complex and the solvent during the melting or crystallization process [1]. Leuco dye based thermochromic materials usually consist of an electron donating chromogenic compound (leuco dye), an electron acceptor (developer) and a matrix component (solvent) [2]. The most common electron-donating chromogenic compounds are phenylmethane and fluoran derivatives bearing a lactone ring moiety. In the lactone ringclosed state these so-called leuco dyes or colour formers are either colourless or weakly yellow coloured [2].

An opening of the lactone ring occurs in reaction with an electron-accepting developer, resulting in the formation of a zwitterionic structure. The conjugated $\pi$-electronic system 
of the dye is extended because of this reaction, and as a result of this, the longest wavelength of absorption peak is shifted from UV to visible range, resulting in coloured dye. By adding the appropriate solvent, the colour forming reaction is allowed to be reversible within the temperature change. Leuco dye-developersolvent systems are coloured in the solid state and by heating above their melting temperature they are transferred into a colourless liquid [2].

The leuco dye colour forming reaction has been known for over 50 years, but the detailed molecular mechanism of the reaction is still unknown. Until 25 years ago, the only model discussed in the literature is a proton-driven mechanism for opening and closing of the ring. According to this model, the acidity of the developer is a measure of its effectiveness in maintaining the equilibrium of the opening of the ring and the closing of the ring paints according to their open-ring colour. In many cases, this simple model fails to explain many experimental results [2].

Thermochromic inks based on cholesteric liquid crystals and thermochromic inks based on leuco dye-developer-solvent systems are commercially available [3]. Thermochromism in the graphics industry has a wide application for the new channel of information communication to the end user. Therefore, the thermochromic mechanism finds its implications in terms of smart packaging, security printing, many promotional and marketing visual [3].

A thermochromic printing ink is a mixture of thermochromic pigments and a binder. The size of microcapsules ranges from 3 to 5 $\mu \mathrm{m}$ which is 10 -times larger than conventional pigment particles [3,4]. Thermochromic printing inks are special chromogenic or colour changing inks which change colour under certain circumstances. They are temperature sensitive inks meaning that they exhibit a colour change with exposure to different temperatures.

Printing ink with encapsulated thermochromic complex systems can have different characteristic activation temperatures, the temperature range in which the thermochromic components actively reflect the visible light of a certain wavelength. Of the complex systems that are united under a unique name of thermochromism, the most commonly used are leuco dyes, while those based on liquid crystals are used in products where the temperature change must be precisely defined, e.g. room temperature, refrigerator, storage capacity of food storage with shorter duration, medical purposes, etc. [3].

Thermochromic materials in today's world find their application in the food industry as indicators of freshness and temperature. That is precisely why today there are indicators on beer bottles, wines, water that point to the ideal drinking temperature. In addition, indicators on baby bottles that have a warning function, and indicators on milk cartons are applied which shows whether the product was properly stored in the refrigerator. In the area of security documents, they are used to quickly and easily identify identity and to hide information.

Up to now, most of the research conducted for the thermochromic printing inks were dealing with dynamic colorimetric properties of mixed thermochromic printing inks [5] or the influence of UV exposure on the thermochromic inks stability [6,7]. Rožić et. al. 2016 showed that different physical and chemical properties of paper doesn't affect the value of the thermochromic ink characteristic temperature, but it influences the shape of the thermochromic ink hysteresis curve [8]. In addition, the printing substrate has a significant influence on thermochromic prints biodegradation ability [913].

Although the mechanism of functionality of thermochromic leuco dye-based inks is relatively well known, there is a lack of information about the influence of paper substrate on thermochromic prints colorimetric characteristics, which is a significant factor from an application perspective. Since the most important characteristics of the thermochromic inks are their temperature-dependent properties and the degree of its reversibility, the aim of this research was to investigate the influence of paper substrate on the colorimetric properties of thermochromic offset prints, i.e. the influence on their colour hysteresis and reversibility of the thermochromic process. 


\section{Materials and methods}

\subsection{Printing substrates and printing ink}

In preparation of the experiment, four different paper samples were used: filter paper (Whatman, hereinafter $\mathrm{F}$ ), 100\% recycled paper (Evercopy+Clairefontaine, hereinafter 100R), bulky (Munken Print White, hereinafter B) and synthetic paper (YUPO, hereinafter $\mathrm{S})$. These papers were selected due to their different physical and chemical characteristics.

One commercially available thermochromic offset ink with an activation temperature of $63^{\circ} \mathrm{C}$ was applied (Chromatic Technologies, Inc.). Below its activation temperature, the print was coloured in burgundy and above its activation temperature the print was coloured in blue (hereinafter BB). The printing trials were carried out using the Prüfbau Multipurpose Printability Tester. The quantity of $1.5 \mathrm{~cm}^{3}$ of ink was applied on the distribution rollers while printing was carried out with the printing force of $600 \mathrm{~N}$. All the papers were printed in full tone.

\section{Results and disscussion}

Figures $1-4$ show the reflectance spectra of thermochromic offset prints on different papers measured during heating and cooling cycles. From the obtained reflectance spectra, it can be seen that reversible colour change is present in all samples. The colour of the prints changes from burgundy to blue during heating process and from blue to burgundy during

\subsection{Colorimetric measurements}

The colorimetric properties of thermochromic samples were described in the CIELAB colour space. Temperature-dependent colorimetric properties were measured using Ocean Optics USB2000+ spectrophotometer and Ocean Optics SpectraSuite software for the calculation of the CIELab values $L^{*}, a^{*}, b^{*}$ and $C^{*}$ from measured reflectance in the spectral range of 400-700 nm (in $1 \mathrm{~nm}$ steps). The D50 illuminant and $2^{\circ}$ standard observer were applied in these calculations. The colour difference between the samples at low and high temperature was calculated using the formula CIEDE2000 (CIE Central Bureau 2004),. Each sample was heated by the Full Cover water block (EK Water Blocks, EKWB; Slovenia). The temperature of the copper plate surface was varied by circulation of thermostatically controlled water in channels inside the water block, which was assured to be up to $\pm 0,5^{\circ} \mathrm{C}$ accurate in the applied temperature region. In each cycle the sample was heated from the $35^{\circ} \mathrm{C}$ to the $75^{\circ} \mathrm{C}$ and then cooled back again to the $35^{\circ} \mathrm{C}$.

cooling process. As it can be seen from the figures $1-4$, reflection spectrophotometric curves is not the same for the same sample at the same temperature for heating and cooling. In addition, it can be seen that the process is continuous and no abrupt change was observed.

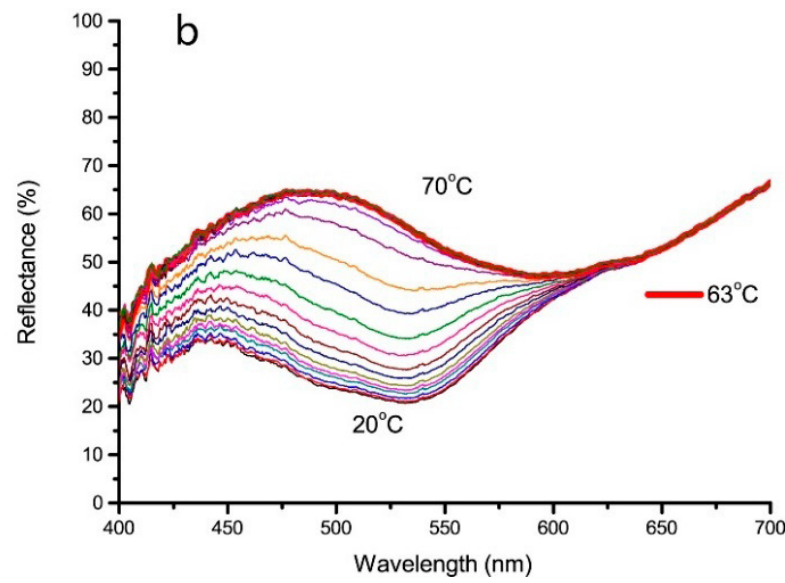

Figure 1. Reflectance spectra of printed filter paper measured during heating (a) and cooling (b) and in red highlighted reflectance curve at $63^{\circ} \mathrm{C}$ 

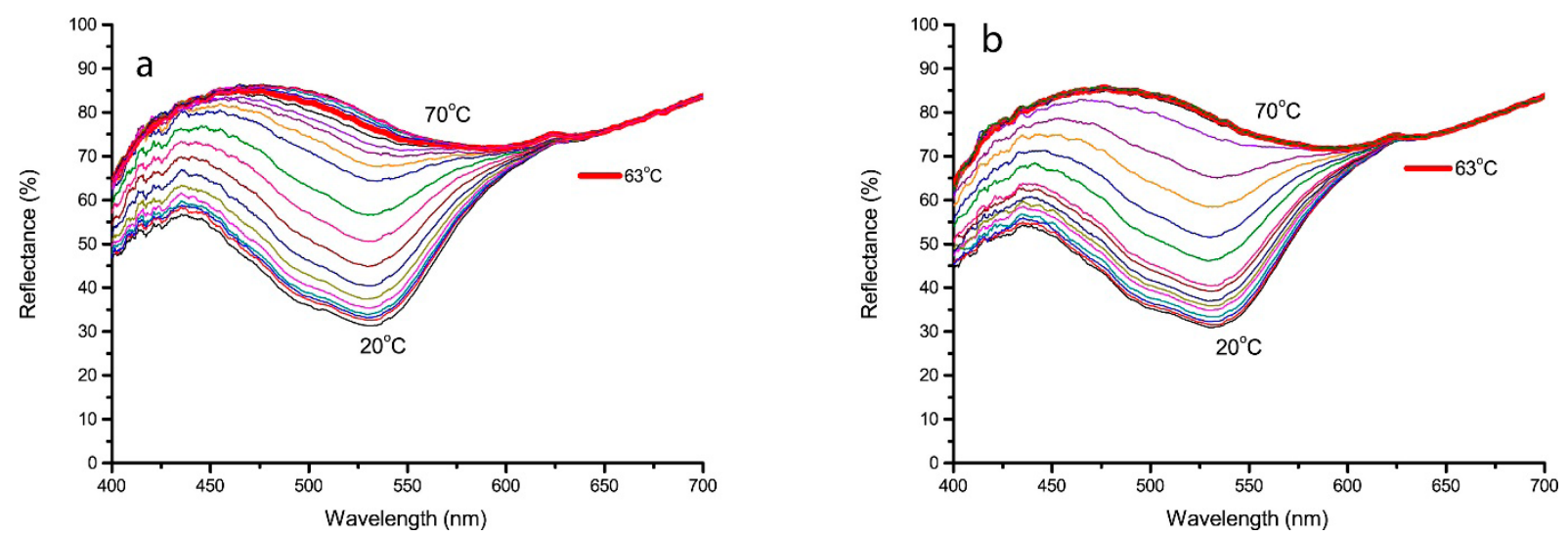

Figure 2. Reflectance spectra of printed synthetic paper measured during heating (a) and cooling (b) and in red highlighted reflectance curve at $63^{\circ} \mathrm{C}$
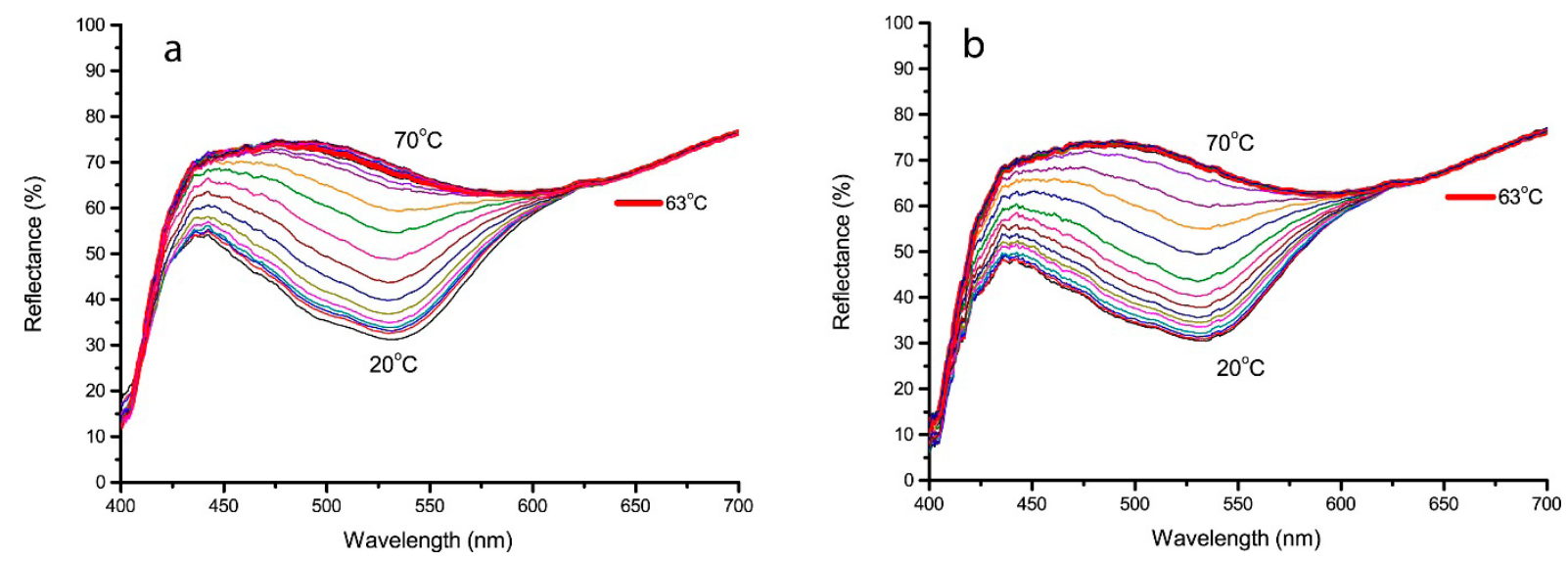

Figure 3. Reflectance spectra of printed bulky paper measured during heating (a) and cooling (b) and in red highlighted reflectance curve at $63^{\circ} \mathrm{C}$
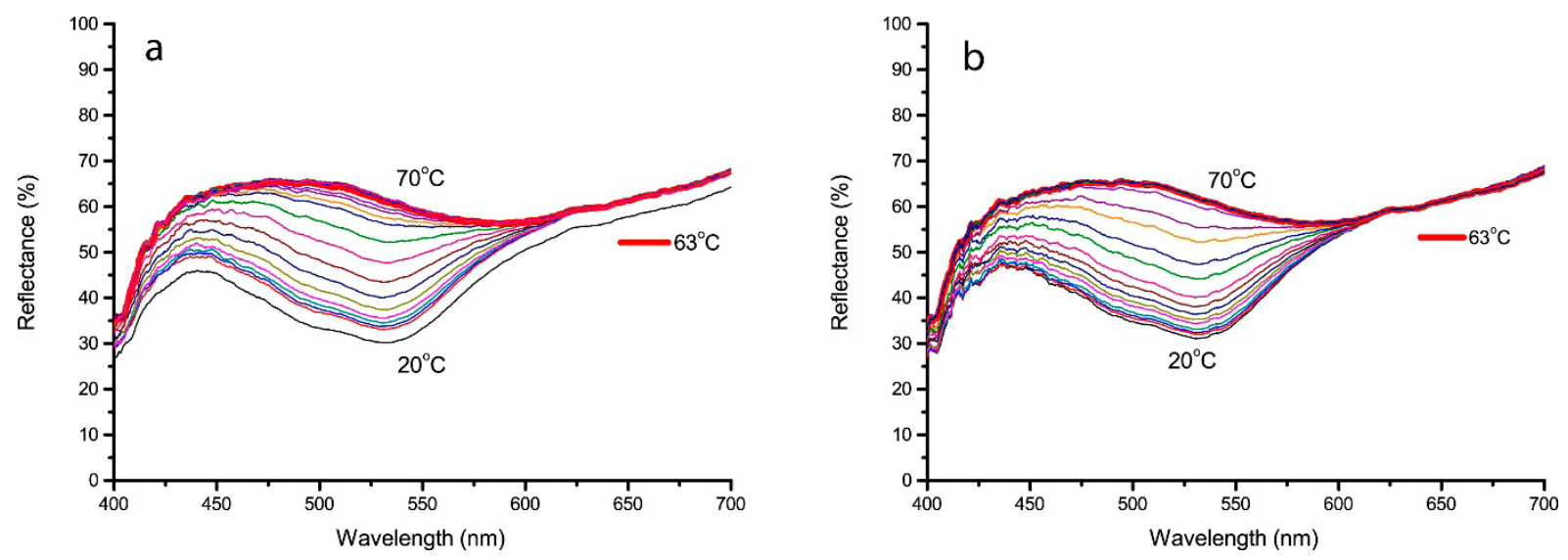

Figure 4. Reflectance spectra of printed $100 \%$ recycled paper measured during heating (a) and cooling (b) and in red highlighted reflectance curve at $63^{\circ} \mathrm{C}$ 
The thermochromic system has a memory, so it is not possible to predict the output without knowing the path that occurred before the current state was reached. This phenomenon is called hysteresis. Colour hysteresis describes the colour of the thermochromic sample as a function of temperature [4]. The reversible thermochromic process depends upon the temperature that can be presented as a change of lightness $L^{*}$ as a function of the temperature T. The reversal process occurs during cooling, but at slightly lower temperatures. The entire $L^{*}(T)$ curve has a form of the loop [4]. In a perfectly reversible process, the thermochromic sample should be returned to the same colour after the entire heating and cooling cycle. The area of the surface defined by the two trajectories shows how similar the colour is when the sample goes through the heating/ cooling cycle. When trajectories are identical, the corresponding area is zero.

Figures $5-8$ show the dependence of CIE $L^{*}$ upon the temperature during heating and cooling cycles of the samples, whereas the solid signs denote the heating process while open signs denote the cooling process. The trajectories obtained by heating are not completely equal to that obtained by cooling for all the samples. A larger area defined by the two trajectories shows bigger differences between colours appearing on the sample when it is heated compared to when it is cooled [4]. The largest area was obtained for the print on filter paper (Fig 5), while the smallest area was obtained for the print on recycled paper (Fig 8). Therefore, the print on recycled paper describes the most similar colours.

In addition to hysteresis, the prints on different papers additionally show different values of CIE Lightness $\left(L^{*}\right)$ which can be explained by the properties of the neat papers. The highest value of lightness is in case of synthetic paper, while the lowest value was obtained on filter paper. This can be explained by the fact that filter paper does not have any additives for achieving certain optical properties, such as optical brighteners. In addition, synthetic paper with high gloss may affect the print Lightness.

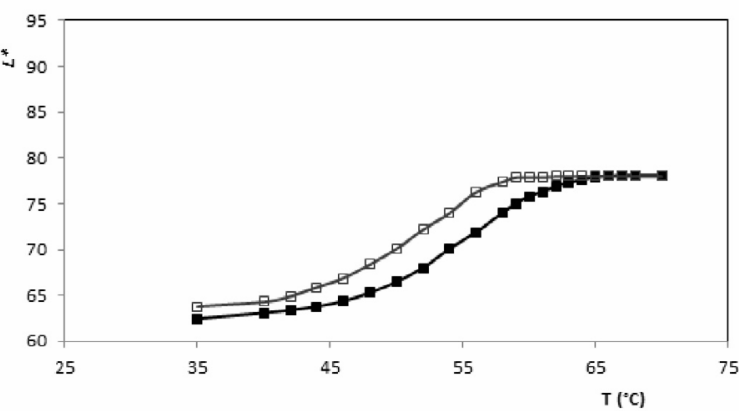

Figure 5. Lightness $L^{*}$ as a function of the temperature of TC print on filter paper during heating (filled symbols) and cooling (open symbols)

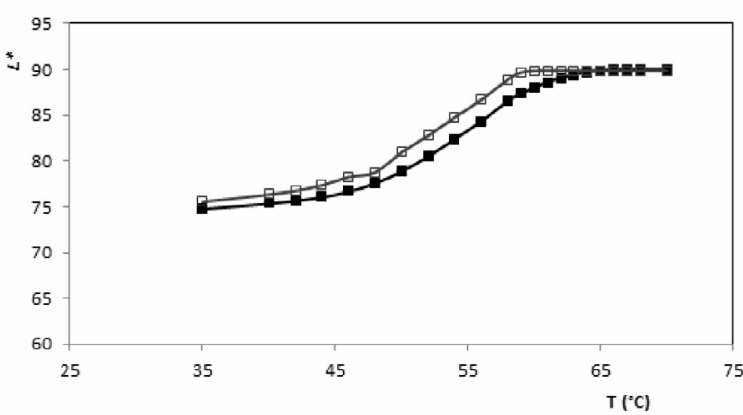

Figure 6. Lightness $L^{*}$ as a function of the temperature of TC print on synthetic paper during heating (filled symbols) and cooling (open symbols)

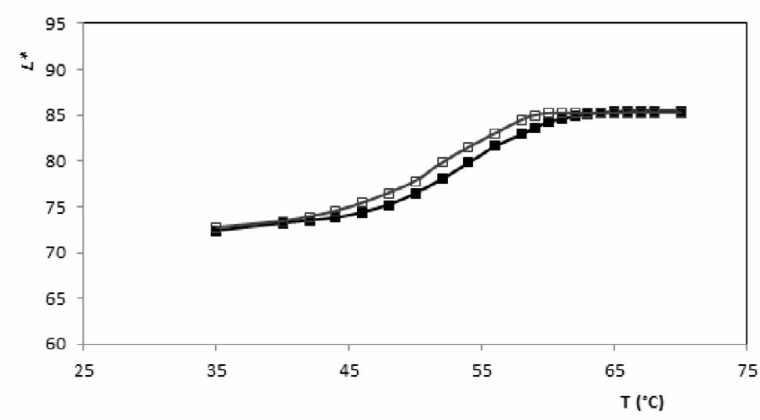

Figure 7. Lightness $L^{*}$ as a function of the temperature of TC print on bulky paper during heating (filled symbols) and cooling (open symbols)

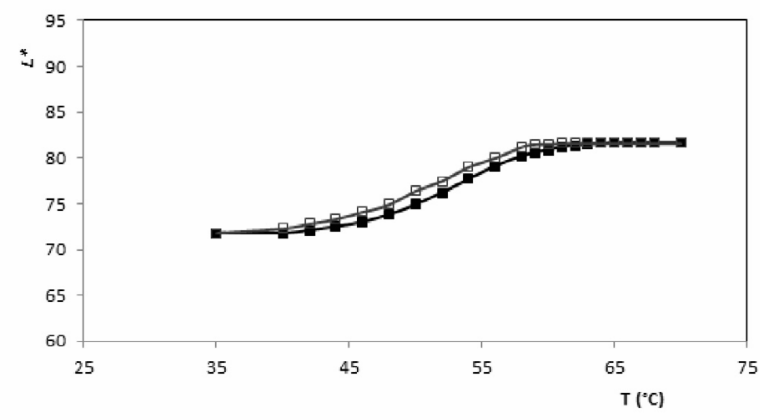

Figure 8. Lightness $L^{*}$ as a function of the temperature of TC print on $100 \%$ recycled paper during heating (filled symbols) and cooling (open symbols) 
The characteristic temperatures of the prints on different papers have been determined according to Kulčar et.al (2010) [4]. The characteristic temperatures determined from of $L^{*}(\mathrm{~T})$ hysteresis is presented in Table 1. Between $\mathrm{T}_{1}$ and $\mathrm{T}_{2}$ process of discoloration occurs, while between $\mathrm{T}_{3}$ and $\mathrm{T}_{4}$ system returns to coloured state. These temperatures can be determined from any two-dimensional graph, in which the hysteresis colour, $a^{*}(\mathrm{~T}), b^{*}(\mathrm{~T}), L^{*}(\mathrm{~T})$ or $C^{*}$ (T) is shown.

Table 1. Characteristic temperatures of the prints on different papers

\begin{tabular}{|l|l|l|l|l|}
\hline & $\begin{array}{l}\text { Filter } \\
\text { paper }\end{array}$ & $\begin{array}{l}\text { Synthetic } \\
\text { paper }\end{array}$ & $\begin{array}{l}\text { Bulky } \\
\text { paper }\end{array}$ & $\begin{array}{l}\text { Recycled } \\
\text { paper }\end{array}$ \\
\hline $\mathrm{T}_{1}\left({ }^{\circ} \mathrm{C}\right)$ & 48.1 & 47.7 & 46.8 & 46.4 \\
\hline $\mathrm{T}_{2}\left({ }^{\circ} \mathrm{C}\right)$ & 61.3 & 61.5 & 60.9 & 59.4 \\
\hline $\mathrm{T}_{3}\left({ }^{\circ} \mathrm{C}\right)$ & 57.5 & 59.1 & 58.5 & 58.5 \\
\hline $\mathrm{T}_{4}\left({ }^{\circ} \mathrm{C}\right)$ & 44.5 & 46.9 & 45.6 & 44.4 \\
\hline
\end{tabular}

From Figures $5-8$ and Table 1 it can be seen that the characteristic temperatures are generally similar. The activation temperature given by the producer $\left(63^{\circ} \mathrm{C}\right)$ more likely closer to $\mathrm{T}_{2}$ is above the obtained temperatures with the highest deviation in the case of recycled paper (59. $\left.4{ }^{\circ} \mathrm{C}\right)$.

The degree of reversibility of a thermochromic sample can be characterized by the opening of colour hysteresis loop at low temperatures. i.e. by total colour difference of a sample measured between heating and cooling at a temperature well below the final chromic temperature [4]. All the samples appear differently during the process of decolourization and colourization. Colour difference between heated and cooled sample reaches the largest values for the print on filter paper.

Table 2 Total colour difference (CIEDE2000) between heated and cooled samples at $35^{\circ} \mathrm{C}$.

\begin{tabular}{|l|l|}
\hline Sample & CIEDE2000 \\
\hline F -BB & 2.26 \\
\hline S - BB & 0.97 \\
\hline B - BB & 0.36 \\
\hline 100R - BB & 0.23 \\
\hline
\end{tabular}

Figure 9 shows the CIEDE2000 total colour difference between the samples in the heated and cooled state as a function of a temperature indicating that the highest colour difference was obtained in TC print on the filter paper. For all the samples, the highest colour difference was obtained in the temperature range from 44 to $62^{\circ} \mathrm{C}$ at a temperature of $59^{\circ} \mathrm{C}$ for print on filter and synthetic paper $58^{\circ} \mathrm{C}$ for print on bulky paper and $56^{\circ} \mathrm{C}$ for print on recycled paper. From Figures 5 - 8 it can be seen that the trajectory of samples obtained by heating are not equivalent to those obtained by cooling. The surface area defined by the two trajectories indicates how similar the colour is while the sample passes through a cycle of heating and cooling. If the trajectories were identical, the surface area would be zero. The surface of the colour hysteresis can be presented by using the total colour difference (CIEDE2000) between the sample in the heated and the cooled state as a function of temperature $[4,8]$. From Figure 9 it can be seen that the largest surface area of previously mentioned curves is in the case of TC print on the filter paper followed by synthetic and bulky paper. The smallest changes were observed in the case of recycled paper.

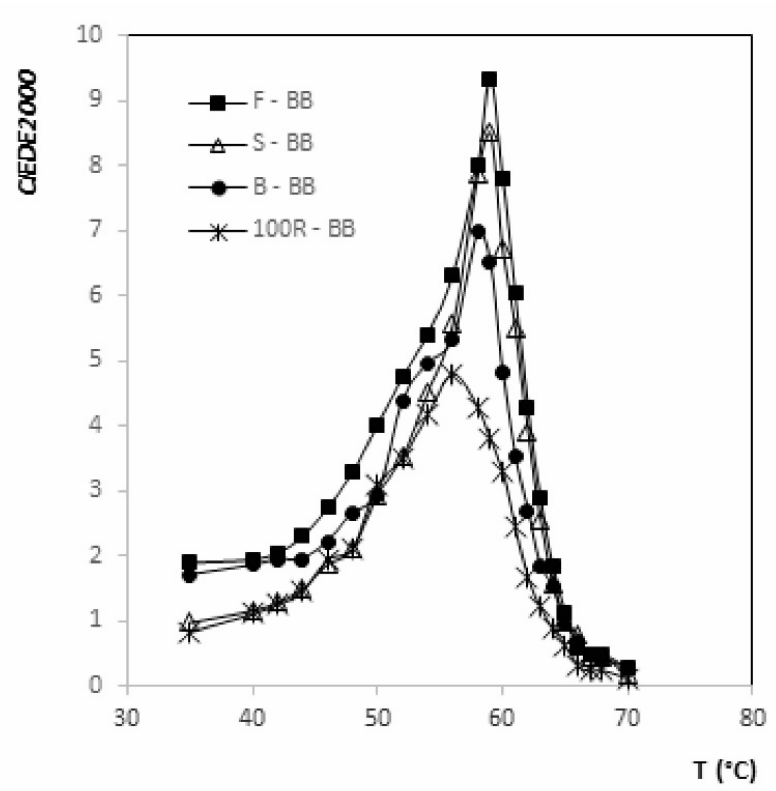

Figure 9. CIEDE2000 differences between the samples in heated and cooled state as a function of temperature 


\section{Conclusions}

The results suggest that depending on the printing substrate thermochromic ink exhibit different dynamic properties during heating and cooling process, which affects the loop form and the area of the hysteresis. In our case, the area of the hysteresis decreases in the sequence filter paper $>$ synthetic paper $>$ bulky paper $>$ recycled paper. Therefore, the future research should take into account the physicochemical properties of printing substrates as well as the interaction of thermochromic ink and a paper. Physicochemical properties of the paper may affect the changes in the position and movement of the microcapsules, as well as their size and dimensional changes during heating and cooling process.

\section{Acknowledgments}

The authors are grateful for the support of the University of Zagreb, Grant under the title "Modifications of conventional graphic materials with nanoparticles and chromogenic materials, and their health safety".

\section{Refrences}

1. Seeboth A. Klukowska A. Ruhmann R. Lötzsch D. Thermochromic Polymer Materials. Chinese J Polym Sci. 2007;25(2):123-35.

2. Seeboth A. Lotzsch D. Thermochromic Phenomena in Polymers [Internet]. Shropshire. UK: Smithers Rapra Technology Limited; 2008. 105 p. Available from: http://scholar.google.com/scholar?hl=en\&bt$\mathrm{nG}=$ Search\&q=intitle:Thermochromic+Phenomena+in+Polymers $\#$

3. Seeboth A. Lotzsch D. Thermochromic and thermotropic materials. Vol. 1. Taylor and Francis. Boca Raton. FL: CRC Press by Taylor \& Francis Group; 2013. 1-221 p.

4. Kulčar R. Friskovec M. Hauptman N. Vesel A. Klanjšek Gunde M. Colorimetric properties of reversible thermochromic printing inks. Dye Pigment. 2010;86:271-7.

5. Kulčar R. Friškovec $M$. Klanjšek Gunde $M$. Knešaurek N. Dynamic colorimetric properties of mixed thermochromic printing inks. Color Technol. 2011;127(6):411-7.

6. Rožić M. Kulčar R. Jamnicki S. Lozo B. Gregor-Svetec D. UV stability of thermochromic ink on paper containing clinoptilolite tuff as a filler. Cellul Chem Technol. 2015;49:693-9.

7. Friškovec M. Kulčar R. Klanjšek Gunde M. Light fastness and high-temperature stability of thermochromic printing inks. Color Technol. 2013;129(3):21422.

8. Rožić M. Vukoje M. Kulčar R. Žužić A. Colorimetric properties of reversible thermochromic ink on different papers. In: Proceedings - 8th International Symposium on Graphic Engineering and Design. 2016. p. 217-23.

9. Vukoje M. Miljanić S. Hrenović J. Rožić M. Thermochromic ink-paper interactions and their role in biodegradation of UV curable prints. Cellulose. 2018 Oct;25(10):6121-38.

10. Vukoje M. Rožić M. Miljanić S. Pasanec Preprotić S. Biodegradation of thermochromic offset prints. Nord Pulp Pap Res J. 2017;32(2):289-98.

11. Vukoje M. Rožić M. Cigula T. The role of adhesion on thermochromic printed cardboard biodegradation. Ann Fac Eng Hunedoara. 2017 Jan 1;15(1):7582.

12. Vukoje M. Rožić M. Thermochromic offset ink paper interactions and print biodegradation. Acta Graph. 2017;28(4):137-47.

13. Vukoje M. Kulčar R. Itrić K. Rožić M. Spectroscopic evaluation of thermochromic printed cardboard biodegradation. In: Proceedings - The Ninth International Symposium GRID 2018. 2018. p. 87-96. 
